\title{
Editorial
}

\section{La marcha de la inflación}

El sistemático aumento de precios observado durante los primeros meses del presente ano, parecen haber convertido a la inflación en el principal quebradero de cabeza del gobierno, dentro del campo económico. No es que no existan otros problemas de igual o mayor magnitud -persistente incremento de la brecha de ingresos y gastos fiscales, reducción de las reservas internacionales netas, etc. - si no simplemente que la inflación por afectar el poder de compra de las familias, tiende rápidamente a transformarse de problema económico en problema político.

Ya para el mes de marzo del presente año, y según los cálculos oficiales del Ministerio de Planificación (PROCESO 431) el costo diario (25.51 colones) de la canasta familiar de alimentos para el área urbana era superior en $41.7 \%$, al salario minimo (18 colones diarios) establecido para el área metropolitana de San Salvador. En el área nural, según la misma fuente, la diferencia del costo de la canasta familiar con relación al máximo salario diario del sector agropecuario era de 83.6\%.

Es evidente, que estos diferenciales entre las remuneraciones por trabajo y el costo de los bienes alimentarios básicos, no se limitan al deterioro del poder adquisitivo de las familias, sino que representa en la práctica una transferencia real de ingresos de un grupo social que únicamente cuenta con las remuneraciones a su fuerza de trabajo como medio de subsistencia, a otro grupo social, mucho más reducido, que por su carácter de propietarios de los medios de producción se encuentran como duehos de los bienes básicos que consume el resto de la población. 
Dado que la variación anual promedio del período enero-marzo (26.4\%) fue superior incluso a la variación anual promedio observada durante el último trimestre de 1989 (21.5\%); el gobiemo del Presidente Cristiani se vio obligado a adoptar una medida que no estaba contemplada dentro del programa inicial de su gobierno: el aumento de los salarios mínimos.

En un discurso a la nación pronunciado el 8 de abril, el mandatario senaló que a partir del 16 del mismo mes entraría en vigencia una nueva tabla de salarios mínimos que aumentaba los salarios vigentes para actividades no-agrícolas en aproximadamente $16.6 \%$ en el área metropolitana de San Salvador; $17.6 \%$ en el resto de municipios; y en $15.0 \%$ para el sector agropecuario.

No obstante estos aumentos, para el mes de abril el costo diario de la canasta familiar de alimentos en el área urbana seguia siendo superior al salario minimo entre un $25.6 \%$, dependiendo del área urbana considerada. Para el área nural, el incremento del salario apenas significaba una leve mejoria, pues la diferencia, entre el costo de la canasta y el salario, se mantenía y el nuevo salario mínimo únicamente representaba 0.57 del costo de la canasta, es decsir se necesitaban prácticamente dos salarios mínimos para cubrir el gasto diario de alimentación.

Como resultado de esta incapacidad de compensar, sin asistencialismo, el deterioro del poder adquisitivo de las familias, el gobierno ha visto cuestionada duramente su política económica por parte de las organizaciones más representativas de los trabajadores, que a través de comunicados han senalado que a pesar de la promesa de favorecer a "los más pobres de entre los pobres", los pobres están ahora más pobres y son más.

Sin embargo, los problemas que le origina al gobierno la reciente aceleración inflacionaria, no termina con las protestas de los sectores laborales organizados, debido a que también es blanco de las criticas de algunas gremiales empresariales que cuestionan las medidas adoptadas para contener la inflación.

De todos es sabido, que uno de los principales factores - sino el principal- de impulso a la inflación to constituye el precio del dólar. Durante el primer cuatrimestre de este afio el tipo de cambio del mercado extrabancario evolucionó de una cotización de venta de 6.75 colones por dólar para el tres de enero a una cotización de venta de 8.15 colones por dólar el 16 de abril del corriente ano, es decir un aumento de apróximadamente $20.7 \%$. 
En tal sentido, la estabilización del precio del dólar se convirtió en uno de los objetivos prioritarios del gobierno al más corto plazo. Para eliminar la presión ejercida sobre el mercado de divisas por el lado de los compradores, el Banco Central de Reserva aplió una política crediticia restrictiva, al restringir el crédito del sistema bancario durante el primer trimestre a únicamente 468 millones de colones, con to que dada la inflación acumulada del período $(7.6 \%)$, el aumento fue en realidad negativo, $-3.1 \%$ apróximadamente, con relación al nivel otorgado en diciembre de 1989. Esta restricción fue mucho más drástica durante los dos primeros meses del ano, ya que la variación del crédito privado entre diciembre de 1989 y febrero de 1990 fue de 163 millones, es decir de únicamente $2.4 \%$, en términos nominales. Por otra parte el crédito al sector público aumentó únicamente el $1.1 \%$ durante el mismo período.

Esta política restrictiva, fue resentida por el sector privado y a mediados de febrero la Cámara de Comercio e Industria senalaba que: "la disminución de la inflación tiene que descansar más en el aumento de la producción que en las restricciones monetarias y crediticias". (EI Mundo, 19 de febrero de 1990). Por otraparte, el principal "Think Tank" del sector privado senalaba la posibilidad de que el gobierno provocara una recesión económica al recordarle "la importancia de que el BCR ejecute una política monetaria compatible a un objetivo de moderado crecimiento del producto para el ano". (FUSADES, Informe Económico NNe 10, abril).

En síntesis, la inflación de este primer cuatrimestre del ano, tasa acumulada de $9.9 \%$ en relación a diciembre del anto anterior y variación promedio de $27.2 \%$, nos indica que de continuar esta tendencia fácilmente se podría alcanzar al final de un ano una inflación acumulada superior al $30 \%$ y una inflación promedio anual de apróximadamente un $25 \%$.

Este tipo de resultados, no sólo le impediría al gobierno alcanzar sus metas de reducir la inflación (en relación al promedio alcanzado en 1989), sino que también le obligaría a improvisar algunas medidas en materia de política salarial con el objetivo de no desgastarse pollticamente de cara a las elecciones del próximo ano, pero al adoptar este tipo de respuestas improvisadas se estaría alejando de su programa y adoptando la filosofía de los gobiernos de la década pasada; administrar la crisis y las coyunturas electorales. 